\title{
Learn it, Live it, Teach it, Embed it: Implementing a whole school approach to foster positive mental health and wellbeing through Positive Education
}

\author{
Erin Hoare · David Bott · Justin Robinson
}

\begin{abstract}
Schools provide unique environments for the implementation of interventions to support the mental health and wellbeing of young people. While promising as an intervention setting, the school system is inherently complex, and any successful intervention or programme must account for, and adapt to, such complexity. Whole-school approaches that comprise multicomponents and promote collaborative and collective action across the school system appear promising for accounting for these complexities. This paper reports the updated implementation processes of one whole-school approach, the Geelong Grammar School Applied Model for Positive Education, for fostering positive mental health and wellbeing among the school community. Drawing upon existing frameworks and from successes observed in the fields of Social and Emotional Learning, mental health prevention, and health promotion, adapted to meet the goals of Positive Education, we propose four interconnecting, cyclical processes; Learn it, Live it, Teach it, Embed it. In combination, these processes assist schools in designing and reviewing ongoing implementation. This study extends the literature to date by synthesising organisational, systems change, education, and anecdotal evidence to identify barriers to implementation and subsequent outcomes of missed, or poorly executed processes. While schools will be unique in factors such as context, specific needs, and available resources, it is envisaged that reporting these processes and potential barriers to success may assist schools with their own future implementation endeavours.
\end{abstract}

Keywords: positive education, student wellbeing, implementation science

\section{Introduction}

There is consensus that optimal mental health should be pursued through both reducing/eliminating psychopathology, and through maximising positive wellbeing [1]. Childhood and adolescence is a critical time for acquiring key skills to support positive mental health and to prevent against mental health problems that may precede mental health disorders [2]. It is known that the first onset of mental disorder usually occurs in childhood or adolescence, however, effective treatment is not usually received until many years later $[3,4]$. This age period offers optimal opportunity to promote positive mental health that may support healthy emotional development into adulthood.

Schools provide unique environments for the implementation of interventions to support mental health and wellbeing of young people, given the opportunity for large population reach and due to pre-existing structures for interventions to occur. A school 'system' is used to refer to the interdependent components with varied functions that interact to produce outcomes in 
educational settings [5]. While promising as an intervention setting, the school system is inherently complex, and any successful intervention or programme must account for, and adapt to, such complexity [5-7]. Whole-school approaches that comprise multi-components and promote collaborative and collective action across the school system appear promising for accounting for these complexities.

This paper reports on the implementation framework of one whole-school approach to fostering positive mental health and wellbeing through Positive Education. Broadly, Positive Education refers to the application of positive psychology in educational contexts to promote positive mental health, allowing students, staff and the wider school community to flourish [810]. The Geelong Grammar School Applied Model for Positive Education (GGS Model) (described in detail elsewhere [8] and in sub-sections below) is a structured framework developed to promote positive mental health within a school community through Positive Education. The GGS Model adopts a whole-school approach and aims to incorporate the complexity of the school setting by implementing the Positive Education philosophy across multiple levels (e.g., students, staff, policies, school ethos) in the school community. The model is based on Martin Seligman's PERMA model of wellbeing [10], updated to include positive health (further described below).

Subsequent developments of the model have previously been described [8, 11, 12], as have initial findings referring to student [13], staff [14] and parent [15] emotional health and wellbeing outcomes. This current study builds on the existing literature by specifically reporting the updated implementation processes of the model, which were developed based on practice wisdom, and successes observed in the mental disorder prevention field [16], Social and Emotional Learning [17] and other fields [18, 19]. This implementation framework comprises four, cyclical, interconnecting processes: Learn it, Live it, Teach it and Embed it. The reporting of processes will further build implementation science in the school-based mental health promotion field, which is currently lacking [20]. While an individual school will be unique in context, specific needs, available resources and other key factors, it is envisaged that reporting these processes and potential barriers to success will assist schools with their own future implementation endeavours.

The overall purpose of this study is to report the implementation framework of one wholeschool approach to Positive Education. This study also aims to describe the potential barriers to success based on both practical/anecdotal experience, and informed by the wider school-based, organisational and implementation literature. Specifically, this study aims to:

1) Describe the development and content of each implementation process of the GGS Model in the context of the relevant evidence base, in particular, three widely adopted frameworks from mental health [16], Social and Emotional Learning [17], and health promotion fields [21];

2) Examine identified barriers to implementation and subsequent outcomes of missed or poorly executed processes, and;

3) Describe implications for practice and propose areas for future research in implementation of Positive Education.

\section{Positive Education}

Positive Education (Pos Ed) aims to foster character strengths (individual positive traits that are widely valued), resilience (the ability to healthily respond to adversity), wellbeing and abilities in the educational setting, providing opportunity for individuals to flourish [22]. Pos Ed is an 
overarching term used for the theories, programmes and approaches that aim to foster positive wellbeing and adaptive functioning in school settings [23]. As described by Slemp et al. [23], Pos Ed has gained rapid momentum in Australia and abroad to meet the need for fostering positive wellbeing and protecting against mental health problems during adolescence. While rapid momentum has led to large-scale initiation of programmes, the exact limitations of Pos Ed are yet to be universally defined, and many complementary and intersecting approaches exist. Pos Ed broadly includes psychosocial skills, including managing emotions, goal setting, and building resilience, in addition to broader concepts such as meaning, purpose and physical health.

The earliest and most widely implemented programme was initiated at an independent Victorian school, Geelong Grammar School (GGS) during a six-month visit by Professor Martin Seligman and colleagues. GGS is an Anglican co-educational boarding and day school with approximately 1,500 students from pre-school to secondary. There are also defining characteristics of GGS, such as a high level of resources, which are considered in the generalisation of the approach to other settings.

\section{Figure 1. The Geelong Grammar School Applied Model of Positive Education} (implementation processes outer level, highlighted grey), originally published in Norrish et al. [8]

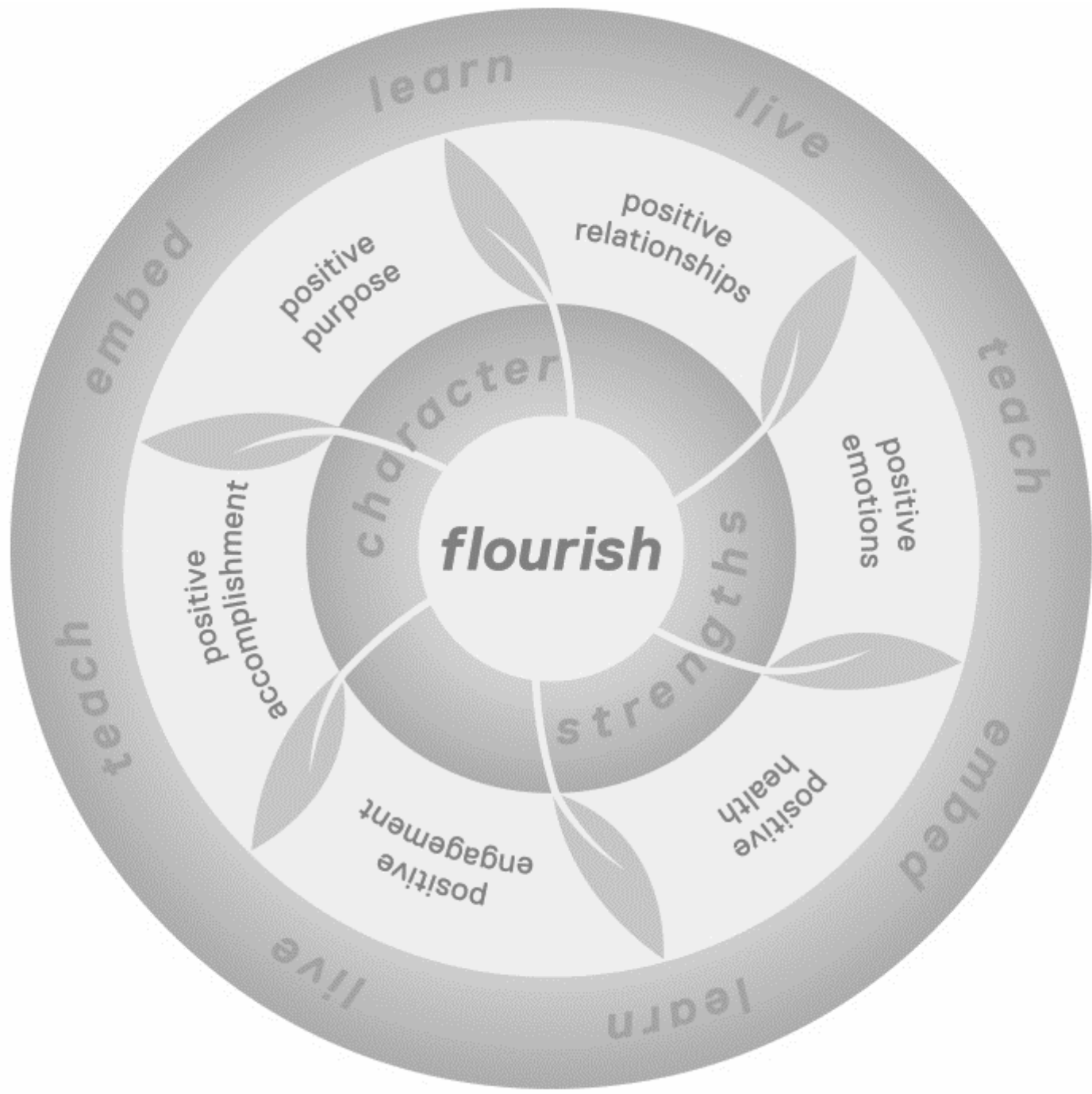


The school, through ongoing contact with Seligman, introduced six key domains of wellbeing bearing similar domains to Seligman's PERMA model, which assumes that wellbeing consists of distinct, teachable elements that individuals universally pursue in living a good life, or as GGS refer to, flourish. The constituent components of 'wellbeing' adopted in the school comprised positive emotions, positive engagement, positive relationships, positive meaning and positive accomplishment [10]. The school also included positive health, given the known connections between physical and mental wellbeing. A broad range of initiatives are delivered at GGS to promote the six domains of wellbeing considered central to allowing an individual to flourish, and the initiatives continue to grow and evolve in response to continuous evaluation and new evidence emerging in the field. Underpinning all efforts is a focus on character strengths, being traits that are universally recognised and morally valued and have been shown relevant in enhancing children's development and wellbeing [8, 24].

The Geelong Grammar School Applied Framework for Positive Education (henceforth referred to as the GGS Model) was developed over five years and subsequently published in 2013, providing one of the earliest frameworks in the Pos Ed field [8]. Further developments since this publication (e.g., the inclusion of Live it) forms the rationale for the current study. The model depicted in Figure 1 above was based on the original framework article, and since updated to demonstrate the cyclical nature of the processes and interconnections across levels.

\section{Whole-school approaches}

Whole-school approaches, being multi-component, collective and collaborative action in the school community, provide optimal opportunity for creating sustained positive change, as opposed to uni-dimensional, standalone programmes [25-27]. The World Health Organization (WHO) described a whole-school approach as holistic with clearly defined policies, processes, activities and structures that aim to support the overall desired outcome, whilst engaging students, teachers, parents and the wider school community members [21]. The benefits of a whole-school approach include targeting multiple internal and external influences, and incorporating individual, classroom and organisational levels to achieve desired outcomes. Effectiveness of such approaches has been demonstrated for mental health and wellbeing outcomes [16, 28, 29], social and emotional learning skills [27], health and lifestyle-related and obesity prevention interventions [30], and problem- and risk-behavioural studies [31, 32].

While the potential beneficial outcomes of whole-school approaches are well-documented, there is a dearth in evidence relating to implementation processes of such interventions. This is particularly the case in Positive Education, an evidence gap previously identified in the literature $[23,33,34]$. A systematic review of 12 school-based positive psychology interventions found that programmes aiming to foster positive emotions (e.g., hope, gratitude, serenity), resilience and character strengths, were related to improved student relationships, wellbeing and academic performance [34]. A limitation reported in this systematic review was that interventions had been delivered in isolated classrooms or through pastoral care, and that wide-reaching and sustainable outcomes should be explored through school-wide approaches. In order to achieve comprehensive understanding of the processes leading to observed successes, and for wider adoption of such interventions across schools, further research and reporting is needed relating to implementation of such approaches.

In the broader mental health and wellbeing field, there has been a growth in whole-school approaches and in implementation science of such approaches. The Australian school-based MindMatters is a national mental health programme that provides a framework to promote mental health and wellbeing in secondary schools [16] and was originally developed based on 
the World Health Organization HPS Framework (henceforth referred to as the HPS framework) [19]. The HPS framework is a whole-school approach emphasising multi-levels (policy and environment through to individual level factors) within a school system. The framework identifies areas for practice and implementation within schools for achieving health outcomes, and includes three key interconnecting areas: (i) curriculum, teaching and learning, (ii) school organisation, ethos and environment, and (iii) partnerships and services. Adopting this approach, the MindMatters programme aims to leverage on existing practice and builds on a school's unique strengths, whilst providing the individual and school-level opportunities to integrate change into the school system. Whilst the psychopathological focus of the MindMatters programme is distinct to the goals of Pos Ed, the implementation processes and the underpinning HPS framework provided important foundations for the approach reported in this current study.

Closely aligned to Pos Ed is Social and Emotional Learning (SEL), which refers to the process of providing young people opportunities to acquire social-emotional competencies (e.g., self and social awareness, relationships skills, responsible decision making) to thrive. In response to agreement among researchers and practitioners that introducing and maintaining effective SEL practices is through whole-school approaches, and from growing popularity and large recent expansion of such programmes, the Collaborative for Academic, Social and Emotional Learning (CASEL) developed the theory of action tool to guide implementation (henceforth referred to as CASEL framework) [35]. The tool aims to provide guidelines and activities to allow integration of SEL within a school, and identify the input required for sustainability. The theory of action proposes that a shared vision of SEL is required among stakeholders within a school, the needs and existing resources are identified, ongoing and embedded professional learning is provided for teachers, evidence-based practices are incorporated into everyday school operations, and continuous improvement is conducted. Processes of the CASEL framework, in addition to previously described frameworks, were used to inform the development of the current proposed framework, adapted and tailored for Pos Ed.

\section{Learn it, Live it, Teach it, Embed it}

Initially highlighted by Seligman et al. [20] in reference to early GGS Pos Ed programmes, a narration of illustrative anecdotal evidence was categorised into Teaching, Embedding and Living [22]. Teaching referred to the explicit Pos Ed classes scheduled as a component of the school curriculum, in which students learnt elements of positive psychology, including resilience, character strengths, positive emotions and relationships, and active and constructive responding. Embedding referred to the active inclusion of Pos Ed concepts in the wider school community, such as in other academic subjects, in sporting activities, and through pastoral care. Living referred to the active enabling of Pos Ed in the day-to-day life of students, building upon the explicit lessons and elements of Pos Ed embedded throughout the school. This early work, further extended by the GGS Model, as described above and demonstrated in Figure 1, served as the foundations for the implementation framework of Pos Ed in the school. This framework is now comprised of four interconnecting cyclical processes: Learn it, Live it, Teach it, Embed it, and, in combination, assists the school to design and review ongoing implementation (Figure 1).

This section details each of the implementation processes, with a description of evidence base supporting its inclusion in the whole-school approach. In short, Learn it refers to the sharing of opportunities as a whole-school community to understand and engage with the science of wellbeing. Live it is enacting evidence-based wellbeing practices in an individual's unique way in their own lives. Teach it is providing students with dedicated time to discover and explore each of the key domains of wellbeing. Embed it is adopting long-term, school-wide policies and 
practices which support and nurture wellbeing within individuals and within the community. It is noted that this framework is designed for schools that have already made the decision and commitment to implement Pos Ed as a whole-school approach, and it is critical to recognise that each process should be considered relative to their unique context and culture.

\subsection{Learn it}

It is proposed that the natural starting point for the school community is to share opportunities as a whole-school community to understand and engage with the science of wellbeing. At GGS, as described in the introductory sections, these comprise positive emotions, engagement, accomplishment, purpose, relationships, and health, underpinned by a focus on character strengths. It is a condition of GGS employment that all new staff (teaching and non-teaching) complete a four-day residential training course to discover and explore elements of personal wellbeing, to learn the foundations of positive psychology, and to develop an understanding of and gain personal experience in the six domains of the GGS Model. Training courses are also offered to parents of students, to be introduced to Pos Ed that is intended to directly enhance their own wellbeing, and indirectly enhance the wellbeing of their children, family and friends. Providing training to staff and parents allows a common language to be shared, and also supports a sense of connection with the school.

The opportunity to provide Positive Education training for all staff may not be feasible for some schools and there are possibilities to enhance learning opportunities without formal training. For example, schools might build staff capacity (e.g., select staff to undertake additional study in Pos Ed) to facilitate and deliver in-house training sessions on aspects of Pos Ed. School leadership committees might research wellbeing frameworks and audit existing wellbeing structures to find suitable approaches for their school. Staff might be provided with resources to introduce key concepts of Positive Education, and such resources might be cost efficient, such as internet sources, readings, and one-off presentations from leaders in the field. Specific case studies of resources extended to the wider school community include through school newsletters and other communications, informing school community members of the key concepts and purpose of Pos Ed. Schools may establish or strengthen networks with local organisations with whom wellbeing-based learning opportunities can be exchanged.

The Learn it component of the implementation model echoes the curriculum, teaching and learning component of the HPS framework, which aims to make use of existing resources, to share resources and learning opportunities. This process aims to provide individuals with the knowledge foundations to support their own wellbeing, and to provide the latest relevant evidence and practice to fulfil teachers' implicit obligation to support and nurture student wellbeing. Educational and developmental resource availability is also a core feature of the MindMatters programme, and mirrors CASEL's theory of action activities: engaging stakeholders, assessing resources and needs, and designing and implementing professional development systems and supports. Consistent across implementation frameworks, and reflected in each of the model processes reported here, is the need to assess the unique needs of a school and ensure that implementation initiatives are tailored to be context-specific to individual schools. While formal training in Pos Ed for staff and parents is an example of how Learn it can be actioned, cost-effective learning opportunities can also emerge from an explicit audit of a school's existing structures and resources for professional development. 


\subsection{Live it}

It is assumed that wellbeing is a deeply personal subject, and, much like assessing school specific needs, individuals are also encouraged to tailor activities to their preferred style and situation. In the GGS context, Live it refers to the day-to-day individual application of the tenets of Pos Ed. For example, GGS staff are encouraged to harness character strengths in difficult situations, actively practice mindfulness and gratitude, foster strong positive relationships with family, friends and colleagues, nurture a healthy lifestyle, and contribute to meaningful communities and projects. It is expected that by endeavouring to live by the principles of Pos Ed, an individual's own wellbeing and the wellbeing of others will be supported. All school community members can be encouraged to be open and proactive in building their own wellbeing, through trialling different practices, living by their values and developing skills associated with wellbeing. An example of how Live it can be actioned in a school community might include deliberate cultural wellbeing practices, such as practicing mindfulness at the commencement of each lesson. Students might explore, trial and share wellbeing strategies, and staff might explore evidence-based teaching strategies to support student wellbeing and learning, such as process praise to foster a growth mindset. It is encouraged that student partnerships are developed to input in initial design and subsequent development of Pos Ed, so that implementation processes are both student and staff informed.

The Live it component is supported by evidence from the SEL field, which proposes that student outcomes are strongly influenced by teachers' social and emotional competence and wellbeing [36]. The CASEL framework outlines that adults should model the traits which they hope to foster within schools, so that they become leaders in embodying the changes they hope to inspire. Similarly, the HPS framework describes staff health promotion and role modelling as key factors driving success in a whole-school approach to fostering positive health. Live it also reflects the partnerships and services component of HPS framework, which aims to encourage involvement of parents, staff and students in the development and refinement of initiatives to achieve health goals. While learning the key tenets that are critical in implementing Pos Ed, the Live it component allows individuals to become authentic role models. Pos Ed concepts become genuine and experiential for school community members, through which sustainable change is more likely to occur.

\subsection{Teach it}

The teaching of Pos Ed refers to the implicit and explicit learning of key ideas and concepts relating to positive wellbeing, and providing students the opportunity to practice the skills and mindsets to allow them to flourish. At GGS, Teach it is actioned through explicit learning in timetabled Pos Ed lessons, originally based on the Penn Resilience Program [37] and the Strath Haven Program [38]. The programmes have been integrated and updated to reflect the skills and knowledge specific to the GGS Model [8]. Although Pos Ed lessons are only formally timetabled from Years 5 through to Year 10, explicit content delivery occurs in younger year levels and commences in GGS's three-year-old kindergarten, where students are taught, for example, about 'green-light thinking' - representing the concept of growth mindset. The explicit programme covers modules found within each domain of the GGS Model (for a full topic list, see Appendix). In addition, all students are exposed to explicit teaching through Pos Ed focus days or through formal pastoral care sessions. Students are actively involved in the development and delivery of such focus days, and this demonstrates the interconnections of the implementation processes with student partnerships, reflecting the Live it domain. 
As described by Slemp et al. [23], a growing range of standalone Pos Ed curricula exist, broadly relating to: resiliency, hope, engagement, relationships, optimism, strengths, exercise and health. The available standalone curricula provide the opportunity for schools to identify which Pos Ed processes meet their unique needs. It is, however, recommended that a curriculum should be underpinned by an overall conceptual framework to successfully implement a wholeschool approach for Pos Ed, further explained in the Embed it section below. As an initial starting point, sequenced curriculum might involve trialling new or tailoring existing dedicated wellbeing lessons and activities, and allocating time and resources for delivery of explicit Pos Ed teaching.

Implicit teaching refers to identifying pre-existing curriculum areas, in contrast to dedicated wellbeing lessons, into which Pos Ed concepts can be incorporated. At GGS, Pos Ed is implicitly taught through a broad range of subjects, allowing the linking of Pos Ed concepts to traditional academic objectives. For example, in mathematics, when students are first introduced to statistics, Dweck's growth and fixed mindsets survey is used to calculate average and distribution for the class [39]. In literature, when studying texts and media, characters are examined in relation to how their emotions affect behaviour and perceptions. Class interactions are encouraged to promote a sense of gratitude, and there is a focus on effective feedback, such as process praise. The goal is for implicit teaching to integrate wellbeing to complement the explicit delivery of Pos Ed.

The Teach it component corresponds closely to the curriculum, teaching and learning in the HPS framework, which emphasises the need for utilising educational resources, integrating the learning areas across the curriculum, and ensuring that curriculum programmes and teaching resources account for all students' learning styles and needs. These processes of the framework are reflected in the MindMatters programme, which recommends introducing explicit lessons pertaining to resilience, but emphasises that the curriculum should be part of a wider wholeschool approach. The CASEL framework aims to develop learning standards and assessments in relation to SEL, and to adopt evidence-based SEL programmes to support skill development among students. Overall, the Teach it component allows a common language for the discussion and understanding of key Pos Ed competencies, and utilises resources for building a school environment that fosters learning and engagement.

\subsection{Embed it}

The goal of Embed it is to support an integrated approach to Pos Ed across the many facets of school life, by ensuring congruence in what is being taught and what is being practiced. At GGS, the school aims to adopt Pos Ed as a philosophy that underpins the school culture. The processes comprising Embed it include collecting wellbeing metrics to assist in refining and developing Pos Ed, updating organisational and student policies to align with the principles of wellbeing, and identifying and connecting all services with the school that support student welfare and wellbeing. At GGS, the school's discipline policy was updated to the 'Kindness, Forgiveness and Reparation Policy.' A school diary serves as explicit documentation around relationship management based on the concepts of kindness and forgiveness, strengths-based and appreciative inquiry underpins the staff development programmes, and written communication with parents incorporates key tenets of Pos Ed. Complementary school-wide processes that align with Pos Ed assist in embedding and sustaining a culture of wellbeing across the school community.

Integrating school-wide policies and activities to foster wellbeing, as reported in the CASEL framework, supports the goal of creating seamless integration, coherence and efficiency across 
the school community. The HPS framework describes school organisation, ethos and environment as a key area for practice, with examples such as developing, implementing and reviewing school guidelines and policies, integrating health services, and using inclusive language in the school community and correspondence. Finally, MindMatters describes using wellbeing data for planning and successful implementation, and provides resources for building a positive whole-school community.

Organisational literature emphasises the need for targeting both micro levels (e.g., explicit Pos Ed lessons to provide the opportunity for students with the skills and competencies to support their own individual wellbeing) and macro levels (e.g., school leadership committing to reviewing and updating policies to mirror the tenets of Pos Ed) for sustainable change to occur [40, 41]. School leadership support, for example, enables the distribution of resources (both personnel and financial) to be allocated to the overall programmes and can therefore strengthen implementation and sustainability. The Embed it component captures the macro level initiatives in a school, and, in combination with the other processes, represent a critical process for successful and sustainable implementation.

\section{Key practice issues}

The proposed implementation framework stems from successes observed in existing SEL and broader health-related models, in addition to a consistent evidence base for whole-school approaches. It is expected that schools are likely to face barriers to successful implementation and it may be unrealistic to assume immediate compliance. Each implementation component does, however, hold unique benefits to achieving a whole-school approach to Pos Ed. We propose that the ordering of Learn it, Live it, Teach it, Embed it is a logical approach for school implementation. The sequence proposes that schools should first provide opportunities for the adults in the school community to learn about the science of wellbeing, then provide time and an environment which enables staff to put into practice and live the key tenets, then prioritise time within the curriculum for students to be taught the skills and knowledge of wellbeing, and finally, to gain maximum benefit, ensure the lens of wellbeing is applied sensitively to each facet of the school.

While we propose the above ordering, we also encourage schools to identify their unique needs and existing opportunities, and this may, in turn, affect the implementation process. For example, school policies and leadership commitment to change to support wellbeing may occur prior to any explicit teaching of Pos Ed being introduced into the curriculum. There are, however, expected outcomes of overlooked or poorly executed processes of the implementation framework. Drawing upon practice wisdom, in addition to organisational [42], systems [43], and educational change [44, 45] literature, potential barriers and likely outcomes of overlooked processes are reported in Table 1 below. The purpose of this section is to allow preparation of strategies to prevent such outcomes, and recognition of common issues if unintended outcomes occur. As previously highlighted, each school will be unique in context and needs, and the issues and potential outcomes that may occur may also be unique. As such, the scenarios described here are examples of potential outcomes, and do not reflect an exhaustive list.

Unintended or unexpected consequences may signal that an implementation component was missed or may require strengthening. For example, if school community members are confused about Pos Ed, there may need to be a review of the learning of the key tenets of the field. Rosenberg and Mosca identified organisation members' attitudes and disposition toward change, fear of the unknown, and lack of understanding of intentions, to be the three most frequently reported reasons for resistance to organisational change [42]. 
Table 1. Processes of change, common issues and potential outcomes of overlooked or poorly executed (indicated by a strikethrough and bolding) processes

\begin{tabular}{|c|c|c|c|c|c|}
\hline \multicolumn{4}{|c|}{ Processes of change } & \multirow{2}{*}{$\begin{array}{l}\text { Common issues } \\
\text { Lack of understanding and } \\
\text { knowledge }\end{array}$} & \multirow{2}{*}{$\begin{array}{l}\text { Potential outcomes } \\
\text { Apathy } \\
\text { Confusion } \\
\text { Anxiety }\end{array}$} \\
\hline Eeath & Live & Teach & Embed & & \\
\hline Learn & Live & Teach & Embed & Perceived hypocrisy & $\begin{array}{l}\text { Frustration } \\
\text { Resentment } \\
\text { Resistance }\end{array}$ \\
\hline Learn & Live & Teach & Embed & Missed opportunities & $\begin{array}{l}\text { Misunderstood } \\
\text { Forgotten } \\
\text { Not prioritised }\end{array}$ \\
\hline Learn & Live & Teach & Embed & $\begin{array}{l}\text { Independent rather than } \\
\text { integrated efforts }\end{array}$ & $\begin{array}{l}\text { Dejected } \\
\text { Ineffective } \\
\text { Loneliness }\end{array}$ \\
\hline Learn & Live & Teach & Embed & $\begin{array}{r}\text { Positive whole } \\
\text { Common } \\
\text { Authenti } \\
\text { Community awar }\end{array}$ & $\begin{array}{l}\text { school change } \\
\text { language } \\
\text { delivery } \\
\text { ness and support }\end{array}$ \\
\hline
\end{tabular}

Thornton et al. described personal mastery as a necessary function for successful change, and that poor outcomes are often observed when major initiatives are implemented into classrooms without sufficient training or support [44]. Factors to lessen resistance might include developing systematic procedures to improve individuals' capacity, developing appropriate communications and employee involvement initiatives, all of which translate to the Learn it process in our proposed framework.

If staff or students become frustrated with or resentful about Pos Ed, there may be discrepancy between the ideal and actual practice. Thornton et al. [42] described that organisations and schools can help or hinder successful implementation, depending on the extent to which community members discuss, identify and are in agreement of the goals and vision of the change [44]. Ball outlined that the development of a school analysis must consider the experiences, views and interpretations of the school community members to truly account for their practical concerns and interests [43]. Overlooking these experiences may contribute to resistance to change, and further efforts might be directed towards tailoring to the unique needs of a school community, encouraging student and staff agency, and thus supporting the goals of Live it in the model of Pos Ed.

Planning and implementation may have been removed from the school leadership agenda, and this may signal the school has not adequately prioritised the teaching of Pos Ed. Thornton et al. outlined that significant institutional change requires high levels of resource co-ordination, and continuous reviewing and realignment [44]. Resource co-ordination may include identifying pre-existing curriculum areas in which Pos Ed could be implemented, and this process within the Teach it component is highly recommended as a priority for schools, particularly when time and resources do not allow the delivery of explicit Pos Ed classes. As described by Rowe and Stewart, increased student participation in the school environment is observed when students have a sense of ownership in the curriculum [45], and further attempts to build student partnerships through Teach it may be targeted if Pos Ed appears misunderstood or forgotten. 
Independent rather than integrated efforts would suggest Pos Ed is yet to be embedded into the school system. Thornton et al. [42] describe that significant organisational change requires continuous reassessment and realignment, and that schools endeavouring change require development of effective and systematic feedback. Whole-school approaches demonstrate effectiveness when initiatives are embedded into the organisational processes and align with the school values and culture [46]. If there are individuals within a school working in Pos Ed in isolation, this may point to the school reviewing how service, policies and practices align to the goals and aims of Pos Ed, and partnerships could be strengthened.

\section{Directions for future work}

Rigorous outcome evaluation is currently underway, exploring the impact of Pos Ed on the wider school community at GGS. It is expected that this piece will advance the literature relating to the effectiveness of key Pos Ed tenets in supporting individuals to flourish, and subsequently provide insight into the effectiveness of the overall implementation approach. While this current piece outlined the implementation processes of the GGS model and discussed the potential outcomes based on organisational, systems thinking and school-based literature, it is acknowledged that this is one proposed model in a rapidly growing and very broad field. It is expected that this model will be further enhanced with the accompanying implementation tool, the Geelong Grammar School Positive Education Road Map, which comprehensively describes each respective sub-processes for Live it, Learn it, Teach it, Embed it (forthcoming). It is envisaged that the road map will further assist schools in implementing Pos Ed and allow tracking of progress for each component. Furthermore, research is planned to pilot the implementation tool at other participating schools at varied stages of their Pos Ed journey, to allow continuous improvement through formative evaluation. A notable limitation of our proposed implementation framework is that information pertaining to cost-effectiveness is not yet included. Future research is planned to examine the impact of implementing Pos Ed based on financial, opportunity, time, and other resource costing, through which further formative evaluation can occur.

\section{Conclusion}

This paper reports the implementation framework of a whole-school approach to fostering positive mental health and wellbeing through Positive Education. Drawing upon the successes observed in mental health prevention, Social and Emotional Learning, and health promotion fields, our framework proposes that sustainable Pos Ed is implemented through: sharing opportunities to learn and engage in the science of wellbeing, enacting evidence-based wellbeing practices in unique and authentic ways, providing students with dedicated time to discover and explore wellbeing, and developing school-wide policies and practices to support wellbeing over time.

While there is no definitive, prescribed temporal ordering of the implementation processes, we propose that unexpected or unintended outcomes may result from overlooked or poorly executed processes and that common issues and possible outcomes should be considered throughout implementation. This current framework will be enhanced through formative evaluation, following implementation across schools at various stages of their Pos Ed 'journey,' and through the Geelong Grammar School Road Map for Positive Education (forthcoming), which will propose specific sub-processes to further depict our implementation approach.

The application of positive psychology in educational contexts provides exciting and promising opportunities in supporting the mental health and wellbeing of individuals and entire school communities. It is critical that the processes by which schools implement Positive 
Education are evidence based, and that barriers and enablers to success are widely reported to further develop the field. It is our hope that Learn it, Live it, Teach it, Embed it, and the surrounding evidence synthesised in this study, may assist schools with their own whole-school implementation endeavours, and, ultimately, support individuals and school communities to flourish.

\author{
Authors \\ Erin Hoare \\ Geelong Grammar School \\ erin.j.hoare@gmail.com \\ David Bott \\ Geelong Grammar School \\ Justin Robinson \\ Geelong Grammar School
}

\title{
Publishing Timeline
}

Received 12 July 2017

Accepted 23 October 2017

Published 12 December 2017

\section{References}

1. Keyes, C.L., Mental health in adolescence: Is America's youth flourishing? American Journal of Orthopsychiatry, 2006. 76(3): p. 395. https://doi.org/10.1037/0002-9432.76.3.395

2. Patel, V., et al., Mental health of young people: A global public-health challenge. The Lancet, 2007. 369(9569): p. 1302-1313. https://doi.org/10.1016/S0140-6736(07)60368-7

3. Kessler, R.C., et al., Age of onset of mental disorders: A review of recent literature. Current Opinion in Psychiatry, 2007. 20(4): p. 359. https://doi.org/10.1097/YCO.0b013e32816ebc8c

4. McGorry, P.D., et al., Age of onset and timing of treatment for mental and substance use disorders: Implications for preventive intervention strategies and models of care. Current Opinion in Psychiatry, 2011. 24(4): p. 301-306. https://doi.org/10.1097/YCO.0b013e3283477a09

5. Elias, M., From model implementation to sustainability: A multisite study of pathways to excellence in socialemotional learning and related school programs. Sustaining professional learning communities: The soul of educational leadership series, 2007: p. 59-95.

6. Lewallen, T.C., et al., The Whole School, Whole Community, Whole Child model: A new approach for improving educational attainment and healthy development for students. Journal of School Health, 2015. 85(11): p. 729-739. https://doi.org/10.1111/josh.12310

7. Hunt, P., et al., A whole school approach: Collaborative development of school health policies, processes, and practices. Journal of School Health, 2015. 85(11): p. 802-809. https://doi.org/10.1111/josh.12305

8. Norrish, J.M., et al., An applied framework for positive education. International Journal of Wellbeing, 2013. 3(2).

9. Oades, L.G., P. Robinson, and S. Green, Positive education: Creating flourishing students, staff and schools. InPsych: The Bulletin of the Australian Psychological Society Ltd, 2011. 33(2): p. 16.

10. Seligman, M., Flourish: A new understanding of happiness and wellbeingand how to achieve them. 2011, London, UK: Nicholas Brealey Publishing.

11. Norrish, J.M., Positive education: The Geelong Grammar School journey. 2015: Oxford Positive Psychology Series. https://doi.org/10.1093/acprof:oso/9780198702580.001.0001

12. O'Connor, M. and G. Cameron, The Geelong Grammar positive psychology experience, In Social and Emotional Learning in Australia and the Asia-Pacific. 2017, Springer. p. 353-370.

https://doi.org/10.1007/978-981-10-3394-0 19 
13. Vella-Brodrick D., N Rickard, and T-C Chin, An evaluation of positive education at Geelong Grammar School: A snapshot of 2013. 2014.

14. Williams, P., M.L. Kern, and L. Waters, A longitudinal examination of the association between psychological capital, perception of organizational virtues and work happiness in school staff. Psychology of Well-Being, 2015. 5(1): p. 5. https://doi.org/10.1186/s13612-015-0032-0

15. Dubroja, K., M. O'Connor, and V. Mckenzie, Engaging parents in positive education: Results from a pilot program. International Journal of Wellbeing, 2016. 6(3). https://doi.org/10.5502/ijw.v6i3.443

16. Wyn, J., et al., MindMatters, a whole-school approach promoting mental health and wellbeing. Australian \& New Zealand Journal of Psychiatry, 2000. 34(4): p. 594-601. https://doi.org/10.1080/j.1440$\underline{1614.2000 .00748 . x}$

17. Graczyk, P., et al., The role of the Collaborative to Advance Social and Emotional Learning (CASEL) in supporting the implementation of quality school-based prevention programs. Journal of Educational and Psychological Consultation, 2000. 11(1): p. 3-6.

18. Bronfenbrenner, U., Ecological systems theory. 1992: Jessica Kingsley Publishers.

19. World Helath Organization. Local Action: Creating Health Promoting Schools. 2000. SCHOOL/00.3, 2003.

20. Harn, B., D. Parisi, and M. Stoolmiller, Balancing fidelity with flexibility and fit: What do we really know about fidelity of implementation in schools? Exceptional Children, 2013. 79(2): p. 181-193. https://doi.org/10.1177/001440291307900204

21. World Health Organization, Promoting health through schools: Report of a WHO expert committee on comprehensive school health education and promotion. 1997.

22. Seligman, M.E., et al., Positive education: Positive psychology and classroom interventions. Oxford Review of Education, 2009. 35(3): p. 293-311. https://doi.org/10.1080/03054980902934563

23. Slemp, G.R., et al., Positive education in Australia: Practice, measurement, and future directions, In Social and Emotional Learning in Australia and the Asia-Pacific. 2017, Springer. p. 101-122. https://doi.org/10.1007/978-981-10-3394-0 6

24. Park, N. and C. Peterson, Moral competence and character strengths among adolescents: The development and validation of the Values in Action Inventory of Strengths for Youth. Journal of Adolescence, 2006. 29(6): p. 891-909. https://doi.org/10.1016/j.adolescence.2006.04.011

25. O'Dea, J., Benefits of developing a whole-school approach to health promotion. 2012, Sydney, Australia: Sydney University Press.

26. Rowe, F. and D. Stewart, Promoting connectedness through whole-school approaches: A qualitative study. Health Education, 2009. 109(5): p. 396-413. https://doi.org/10.1108/09654280910984816

27. Durlak, J.A., et al., The impact of enhancing students' social and emotional learning: A meta-analysis of school-based universal interventions. Child Development, 2011. 82(1): p. 405-432. https://doi.org/10.1111/j.1467-8624.2010.01564.x

28. Nielsen, L., et al., Promotion of social and emotional competence: Experiences from a mental health intervention applying a whole school approach. Health Education, 2015. 115(3/4): p. 339-356. https://doi.org/10.1108/HE-03-2014-0039

29. Wells, J., J. Barlow, and S. Stewart-Brown, A systematic review of universal approaches to mental health promotion in schools. Health Education, 2003. 103(4): p. 197-220. https://doi.org/10.1108/09654280310485546

30. Charlebois, J., Y. Gowrinathan, and P. Waddell, A review of the evidence: School-based interventions to address obesity prevention in children 6-12 years of age. Toronto, Canada: Toronto Public Health, 2012.

31. Vreeman, R.C. and A.E. Carroll, A systematic review of school-based interventions to prevent bullying. Archives of Pediatrics \& Adolescent Medicine, 2007. 161(1): p. 78-88. https://doi.org/10.1001/archpedi.161.1.78

32. Fletcher, A., C. Bonell, and J. Hargreaves, School effects on young people's drug use: A systematic review of intervention and observational studies. Journal of Adolescent Health, 2008. 42(3): p. 209-220. https://doi.org/10.1016/j.jadohealth.2007.09.020

33. Waters, L., et al., Positive Education. Wellbeing, recovery and mental health, 2017: p. 245. Cambridge, United Kingdom: Cambridge University Press. https://doi.org/10.1017/9781316339275.021 
34. Waters, L., A review of school-based positive psychology interventions. The Australian Educational and Developmental Psychologist, 2011. 28(02): p. 75-90. https://doi.org/10.1375/aedp.28.2.75

35. Weissberg, R.P., P. Goren, and C. Domitrovich, Effective social and emotional learning programs. 2012, CASEL.

36. Jennings, P.A. and M.T. Greenberg, The prosocial classroom: Teacher social and emotional competence in relation to student and classroom outcomes. Review of Educational Research, 2009. 79(1): p. 491-525. https://doi.org/10.3102/0034654308325693

37. Gillham, J., et al., The Penn Resiliency Program. Unpublished manual, University of Pennsylvania, Philadelphia, 1990.

38. Reivich, K., et al., Positive psychology program for high school students: Lessons for the pleasant life, the good life and the meaningful life. Unpublished manuscript, 2003.

39. Dweck, C.S., Mindset: The new psychology of success. 2006: Random House.

40. Harris, A., Distributed leadership and school improvement leading or misleading? Educational Management Administration \& Leadership, 2004. 32(1): p. 11-24. https://doi.org/10.1177/1741143204039297

41. Hopkins, D., Powerful learning: Taking educational reform to scale. 2011: Education Policy and Research Division, Office for Policy, Research and Innovation, Department of Education and Early Childhood Development. State of Victoria, Australia.

42. Rosenberg, S. and J. Mosca, Breaking down the barriers to organizational change. International Journal of Management and Information Systems, 2011. 15(3): p. 139. https://doi.org/10.19030/ijmis.v15i3.4650

43. Ball, S.J., The micro-politics of the school: Towards a theory of school organization. 2012: Routledge.

44. Thornton, B., T. Shepperson, and S. Canavero, A systems approach to school improvement: Program evaluation and organizational learning. Education, 2007. 128(1): p. 48.

45. Rowe, F. and D. Stewart, Promoting connectedness through whole-school approaches: Key elements and pathways of influence. Health Education, 2011. 111(1): p. 49-65.

https://doi.org/10.1108/09654281111094973

46. Stewart, D., et al., Promoting school connectedness through whole school approaches. Health Education, 2007. 107(6): p. 524-542. https://doi.org/10.1108/09654280710827920 


\section{Appendix. Positive Education curriculum modules}

\section{Positive Relationships}

- $\quad$ Empathy and compassion

- $\quad$ Forgiveness

- $\quad$ Leadership and teamwork

- $\quad$ Social intelligence

\section{Positive Emotions}

- Emotional intelligence

- Gratitude

- $\quad$ Positivity

- $\quad$ Self-regulation

\section{Positive Health}

- Mind-body connection

- $\quad$ Physical wellbeing

- $\quad$ Personal intelligence

- $\quad$ Resilience

\section{Positive Engagement}

- Creativity

- Curiosity and interest

- Flow

- Motivation

\section{Positive Accomplishment}

- Decision making

- Goal orientation

- Grit and persistence

- $\quad$ Mindsets

\section{Positive Purpose}

- $\quad$ Care giving

- Character development

- $\quad$ Core values

- $\quad$ Sense of meaning 